Karstenia 56: 1-4

\title{
Honorary Doctor Juhani Ruotsalainen - In memoriam
}

\author{
SEPPO HUHTINEN
}

HUHTINEN, S. 2016: Honorary Doctor Juhani Ruotsalainen - In memoriam. - Karstenia 56: 1-4. HELSINKI. ISSN 0453-3402.

Seppo Huhtinen, Herbarium, University of Turku, FI-20014 Turku, Finland; e-mail: sephuh@utu.fi

Juhani Ruotsalainen died on $5^{\text {th }}$ of February 2016, at the age of 78 years. A very well liked and fit man was suddenly taken away by a short, severe bout of pneumonia. This was a strike out of the blue for so many Finnish mycologists professionals, students, skilled amateurs, doctoral students, mycological club members - and for naturalists, icefishermen etc.

Juhani was born 20.VIII,1937 in Ruokolahti, southeastern Finland. He made his working career in construction sites, mainly as a Master builder. This was later turned into an anecdote, since a Master builder is responsible for the building to be exactly where it should be, not a millimetre to the right or the left. In his retirement years, a millimetre was huge compared with microns which are used in fungal microscopy. He did both jobs well!

Juhani and his wife Kirsti spent their whole adult life together. In the 60's, construction work took Juhani to the Kuopio area in eastern Finland where the family now had five children.

He developed a keen interest in fungi twenty years later. But it had already begun when, as a youngster he was collecting edible fungi with his grandmother. I remember Juhani recalling that even at a young age he became fascinated about a very bright and beautiful Russula bypassed and left in the forest. Juhani took the trouble to col- lect it and take it to the local herbarium. He was happy to learn he had collected the northernmost Russula aurea in Finland. This, together with the luxurious forests around Kuopio, marked the start of his career as a very skilled amateur.

In his article in 1991 about "life with fungi", he wrote almost like a poet: "Those steep slopes with arching spruces, with their sturdy bases over one meter in diameter, and the lowermost branches forming a shady archway under which a man can walk unbent ..... can one image a better place to hunt for mushrooms ..... and I could enjoy this mycological and emotional paradise for some years". Destiny was poetic too, this forest was the type locality for another very beautiful Russula described by Juhani and Jukka Vauras and with a rather poetic name too, namely Russula taigarum. By that time Juhani was already a commercial mushroom consultant and had established the local mushroom club - for which he also was the Chair for the next 12 years.

Rather quickly Juhani became most interested in Russula in particular and a quality microscope was bought by the Club. That, and numerous congresses starting with the Nordic Congress in Korpilahti in 1986, as well as collection trips and other mycological events, such as advanced courses, expanded his knowledge. He participated in eight Nordic congresses. Another 


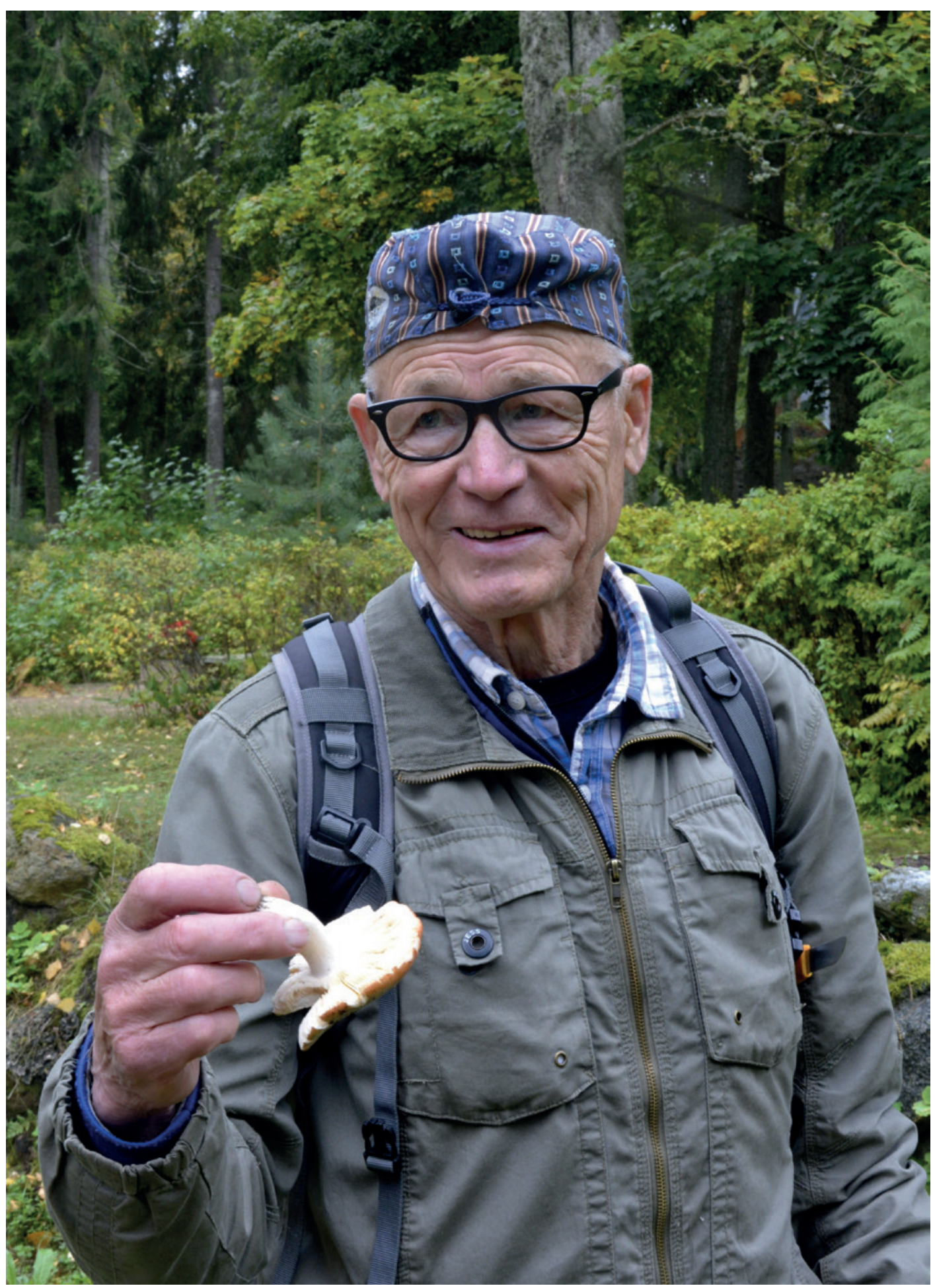

Juhani Ruotsalainen in Kääriku, Estonia 2015. - Photo: T. Siuvatti 
set of events was the mycological co-operation with Estonians, resulting in nearly ten joint collection trips. Soon we had a mycologist able to answer the frequent difficult questions about a difficult genus. Studying type collections, especially those of Romagnesi, was the next step. It was always nice to observe that Juhani was not ashamed that he had not learned English, but he was still teaching about Russulas to foreign mycologists during congresses - in fluent Finnish! With close colleagues he made over 40 collection trips from northern Norway to Italy.

During his mycological career Juhani described 11 new species of Russula, mainly with Jukka Vauras. From first to last these are: $R$. olivina Ruots. \& Vauras, $R$. taigarum Ruots. \& Vauras, $R$. groenlandica Ruots. \& Vauras, $R$. olivobrunnea Ruots. \& Vauras, R. fulvograminea Ruots., Sarnari \& Vauras, $R$. aurantioflammans Ruots., Sarnari \& Vauras, $R$. renidens Ruots., Sarnari \& Vauras, $R$. rivulicola Ruots. \& Vauras, $R$. vinososordida Ruots. \& Vauras, $R$. graminea Ruots., H. Unger \& Vauras and $R$. pyriodora Ruots. Because of his keen in situ photography and detailed microscopical examinations, he also realized there were many new ones just waiting to be named. But the time to help Juhani in writing those articles seemed always to be short. Hence many of those are now known amongst Finnish mycologists as working names only, but easily recognized in the field.

He also had a sharp eye for other groups, so not all his nearly 10000 collections are Russulas. For example one day he came back from the forest with only edible fungi, but had put aside a "different" Hydnum rufescens. At that time, not very many were interested in the microscopic examination of such a "dull" species. He was right, there was something odd, and definitely odd under the microscope and we missed describing $H$. ellipsosporum as new by only few weeks! Another example would be realizing during a normal spring foray that he had hit a site with something different again: Gyromitra longipes, highlighting his keen observational skills.

Juhani sometimes reckoned that fungal studies had a downside too. They seemed to take too much time from fishing, especially icefishing. I was privileged to learn from the "Meister" during hundreds of hours on icy lakes. Sometimes being silent, sometimes discussing life, sometimes telling the apprentice how to do it. His cabinet with trophies was absolutely loaded, starting from Finnish championships to our small duels on ice. He also was a pedantic man: never will I dare to make a wrong kind of fire for grilling sausages! There was often only one correct way for him.

In 2010 Juhani was awarded an honorary doctoral degree in the same promotion as to our Nobel-winning president. The construction site worker had gone a long way in science. Juhani's legacy will be kept safe in KUO, as well as the innumerable precise type studies he made. For example, three collections of the same type comprised of two fruitbodies and a spore print were found to be all different species, since nothing seemed to match exactly to the protologue. So, one can really rely on his drawings and observations. Because of that we were starting a new series of articles with Juhani: "Type studies in Russula". Unfortunately he never saw the first in the series, published in Karstenia a few days before his death.

To honour our friend in a unique way, this issue of Karstenia contains three articles where a new species bears the epithet "suecica", one of them being of course a Russula (Ruotsalainen in Latin is "suecica"). Ruotsalainen in Latin is "suecica". He will be sorely missed by all field mycologists. 
